\title{
Research of quality evaluation of PV power generation project based on the extension theory
}

\section{Dong Wang}

college of management, Xi'an University of Architecture and Technology, Xi'an 710000, China

Keywords: photovoltaic (pv) power generation projects; Extension theory; The matter-element model; Quality evaluation

\begin{abstract}
In order to make a further promotion and development of photovoltaic power generation project, this paper brings the extension theory in photovoltaic power generation project quality evaluation and builds the photovoltaic power generation project extension evaluation index system and model on the basis of matter-element theory and extension analysis. Ranking the evaluating projects by calculating the indicators compared with the correlation of evaluation degrees. The paper takes three photovoltaic power generation project in Shaanxi in 2012 as an example, expounding the model is reasonable and reliable. The empirical results give a best reflection on the quality of the photovoltaic power generation project, which provide a scientific basis for the project decision. The paper results provide a new thought for quality assessment of photovoltaic power generation project, enriching the photovoltaic power generation project evaluation method.
\end{abstract}

\section{Introduction}

With China's economic development pattern transformation and adjustment of industry technology structure, how to improve the consumption structure of energy relying mainly on coal and the environmental pollution following by has become a new period of the current key problems to be solved in our country. Improve the situation that sacrificing environment for economic growth based on long-term and sustainable development needs to develop renewable energy. Renewable energy engineering office based on photovoltaic power generation is mainly used to solve the current environmental pollution and fossil energy depletion, which has good value in developing scale and business development prospects, and helps to achieve social, economic, and ecological development.

Photovoltaic power generation project generally contain multiple quality evaluation indicators, which are often contradictory and restricted with each other. Laying particular stress on different evaluation indexes, there will be different solutions. Decision makers often face the problem: how to consider the various indicators and choose a scheme that meets all the index factors from a number of selections. In order to solve such decision problems, this paper applies extension theory to the photovoltaic power generation project quality comprehensive evaluation, introducing the basic steps of extension evaluation in detail, and taking photovoltaic power generation project in shaanxi province in 2012 as an example to verify the feasibility of this method.

\section{Introduction to the theory of extenics}

Extension theory is put forward by the Chinese scholar CaiWen and used to study the theory of matter element and its transformation. In extension theory, the matter-element is a basic descibe things, which is expressed by an orderly triple $\mathrm{R}=(\mathrm{N}, \mathrm{c}, \mathrm{V})$. N,c,P is called three elements of matter-element, among which $\mathrm{N}$ represents objects ,c means the name of a factor and $\mathrm{V}$ is the value of $\mathrm{N}$ on $\mathrm{c}$.

We establish correlation functions by introducing the concept of distance in extenics, which is used to describe the degree of a factor that element of a domain. Through correlation functions can quantitatively and objectively describe elements have a certain degree of nature and its process of quantitative change and qualitative change: define $\mathrm{x}$ for real axis, $\mathrm{X} 0=<\mathrm{a}, \mathrm{b}>$ for any interval on the real field [1], 


$$
\rho\left(\mathrm{x}, X_{0}\right)=\left|\mathrm{x}-\frac{\mathrm{a}+\mathrm{b}}{2}\right|-\frac{\mathrm{b}-\mathrm{a}}{2}
$$

said the distance between $\mathrm{X}$ and X0.

\section{To establish photovoltaic power generation project extension matter-element evaluation model}

3.1 Determine the photovoltaic power generation project extension matter-element evaluation 3-1-1 To establish photovoltaic power generation project quality evaluation index system

On the basis of the decisive factors in photovoltaic power generation project and combined with the solar energy resources evaluation method, we set up evaluation index system of photovoltaic power generation project and use the G1 method to determine the index weight $\mathrm{W}$. The results are shown in table 1.

Table.1:PV power generation project quality evaluation index system

\begin{tabular}{|c|c|c|c|}
\hline $\begin{array}{c}\text { Objective } \\
\text { level A }\end{array}$ & $\begin{array}{l}\text { Criteria } \\
\text { level B }\end{array}$ & Index level C & weight W \\
\hline \multirow{14}{*}{$\begin{array}{l}\text { Shaanxi } \\
\text { photovoltaic } \\
\text { power } \\
\text { generation } \\
\text { project } \\
\text { quality } \\
\text { evaluation } \\
\text { index system }\end{array}$} & \multirow{3}{*}{$\begin{array}{l}\text { natural } \\
\text { factor }\end{array}$} & The local solar energy resource stability C1 & 0.065 \\
\hline & & The average annual solar total radiation (MJ per M2) C2 & 0.065 \\
\hline & & The annual average sunshine hours ( $h$ ) C3 & 0.065 \\
\hline & \multirow{5}{*}{$\begin{array}{l}\text { investment } \\
\text { intensity }\end{array}$} & Project planning land use(hm2) C4 & 0.085 \\
\hline & & $\begin{array}{l}\text { The occupation of land quantity per unit of output (hm2 per a } \\
\text { hundred million } \mathrm{kw} \cdot \mathrm{h}) \mathrm{C} 5\end{array}$ & 0.085 \\
\hline & & Unit land area of investment(millions per hm2) C6 & 0.085 \\
\hline & & $\begin{array}{l}\text { Unit land area environmental protection investment（million } \\
\text { yuan per hm2） C7 }\end{array}$ & 0.085 \\
\hline & & Dynamic investment unit kw（yuan per KWp）C8 & 0.085 \\
\hline & \multirow{3}{*}{$\begin{array}{l}\text { intensity of } \\
\text { output }\end{array}$} & The number of hours in effective utilization ( $h$ ) C9 & 0.075 \\
\hline & & average annual energy output (a hundred million $\mathrm{KW} \bullet \mathrm{h}$ ) C10 & 0.075 \\
\hline & & $\begin{array}{l}\text { Unit of land area Power generation (a hundred millionkw } \bullet h \\
\text { per hm2) C11 }\end{array}$ & 0.075 \\
\hline & \multirow{3}{*}{$\begin{array}{l}\text { fiscal } \\
\text { charges }\end{array}$} & After-tax capital profit margin (\%) C12 & 0.052 \\
\hline & & Dynamic total investment (millions of yuan) C13 & 0.051 \\
\hline & & average amount of tax (ten thousand yuan per capita ) C14 & 0.052 \\
\hline
\end{tabular}

3-1-2 To determine classical field matter-element

Classical field is used to represent the scope of a certain evaluation index. Assuming that the photovoltaic power generation project is divided into $\mathrm{j}$ degrees, and an evaluation project of the classical field matter-element is:

$$
R_{o j}=\left(N_{o j}, c_{i}, V_{0 j i}\right)=\left[\begin{array}{ccc}
N_{o j}, & c_{1}, & V_{o j 1} \\
& c_{2}, & V_{0 j 2} \\
& \vdots & \vdots \\
& c_{i}, & V_{0 j i}
\end{array}\right]=\left[\begin{array}{ccc}
N_{o j}, & c_{1}, & \left\langle a_{o j 1}, b_{o j 1}\right\rangle \\
& c_{2}, & \left\langle a_{o j 2}, b_{o j 2}\right\rangle \\
\vdots & \vdots \\
& c_{i}, & \left\langle a_{o j i}, b_{o j i}\right\rangle
\end{array}\right]
$$

$\mathrm{N} 0 \mathrm{j}$ is the evaluation grade divided by the $\mathrm{j}$ type; $\mathrm{Ci}$ is the $\mathrm{I}$ th $(\mathrm{I}=1,2, \ldots, \mathrm{n})$ evaluation index; $\mathrm{V} 0 \mathrm{ji}=<\mathrm{a} 0 \mathrm{ji}$ b0ji $>$ is classical field of each evaluation index for N0j [4].

3-1-3 To determine joint domain matter-element

Joint domain refers to the evaluation index of the full range, it is the union set of the corresponding classical domain[4]. Photovoltaic power generation project section domain matter-element can be represented as the following matrix: 


$$
R_{p}=\left(N_{p}, c, V_{p i}\right)=\left[\begin{array}{ccc}
N_{p}, & c_{1}, & V_{p 1} \\
& c_{2}, & V_{p 2} \\
\vdots & \vdots \\
c_{i}, & V_{p i}
\end{array}\right]=\left[\begin{array}{ccc}
N_{p}, & c_{1}, & \left\langle a_{p 1}, b_{p 1}\right\rangle \\
c_{2}, & \left\langle a_{p 2}, b_{p 2}\right\rangle \\
\vdots & \vdots \\
c_{i}, & \left\langle a_{p i}, b_{p i}\right\rangle
\end{array}\right]
$$

Among them, ci $(I=1,2, \ldots, n)$ represents the evaluation index of photovoltaic (pv) power project; Vpi is full scope of evaluation index c, that is the section domain.

3-1-4 To determine the evaluation matter-element

According to the measured data of the indicators to the evaluating project, the evaluating matter-element can be determined as follows:

$$
R=(N, c, V)=\left[\begin{array}{ccc}
N, & \mathrm{c}_{1}, & \mathrm{~V}_{1} \\
& \mathrm{c}_{2}, & \mathrm{~V}_{2} \\
& \vdots & \vdots \\
& c_{i}, & V_{i}
\end{array}\right]
$$

$\mathrm{N}$ in the function represents the evaluating object; $\mathrm{C}$ means all the evaluation index of the object, $\mathrm{V}$ is the measured data of each index.

\section{3-2 Calculation of the associated values}

In the theory of extenics we use the correlation function to describe the certain degree of elements in a domain. The computation formula is as follows:

$$
K_{\mathrm{j}}\left(\mathrm{v}_{\mathrm{i}}\right)=\left\{\begin{array}{lc}
-\frac{\rho\left(V_{\mathrm{i}}, V_{\mathrm{joj}}\right)}{\left|V_{\mathrm{oji}}\right|} & \left(\mathrm{V}_{\mathrm{ij}} \in V_{\mathrm{j}}\right) \\
\frac{\rho\left(\mathrm{V}_{\mathrm{i}}, V_{\mathrm{oj}}\right)}{\rho\left(\mathrm{V}_{\mathrm{i}}, V_{\mathrm{pi}}\right)-\rho\left(\mathrm{V}_{\mathrm{i}}, V_{\mathrm{oji}}\right)} & \left(\mathrm{V}_{\mathrm{ij}} \notin V_{\mathrm{j}}\right)
\end{array}\right.
$$

$\mathrm{Kj}(\mathrm{Vi})$ is the correlation ith evaluation index belongs to the jth evaluation class; $\rho$ (Vi, Voji) is the distance between $\mathrm{Vi}$ and Voji; $\rho(\mathrm{Vi}, \mathrm{Vpi})$ is the distance of $\mathrm{Vi}$ and $\mathrm{Vpi}$; module for interval < aoji, boji $>$ [3].

\section{3-3 To determine the level of comprehensive evaluation}

Assuming that $\mathrm{Wi}$ is the weight coefficient of the ith evaluating index ci,multi-index comprehensive evaluation grades correlation $\mathrm{Kj}(\mathrm{N})$ of evaluating objects $\mathrm{N}$ on evaluating on evaluating class $\mathrm{j}$ is as follows:

$$
K_{\mathrm{j}}(N)=\sum_{\mathrm{i}=1}^{\mathrm{n}} \mathrm{w}_{\mathrm{i}} \mathrm{k}_{\mathrm{j}}\left(\mathrm{x}_{\mathrm{i}}\right)
$$

The greater $\mathrm{Kj}(\mathrm{N})$ value is, the higher degree of association between $\mathrm{N}$ and $\mathrm{j}$. MaxKj $(\mathrm{N})$ represents the evaluation degree which $\mathrm{N}$ belongs to.

For evaluating projects in the same evaluation grades, we usually calculate characteristic value $\mathrm{j}^{*}$ to distinguish between the advantages and disadvantages. According to the value of $\mathrm{j}^{*}$, we can rank the projects in the same evaluating degree[3]. $\mathrm{J}^{*}$, the greater $\mathrm{j}$ is ,the better comprehensive quality of the project will be.

$$
j^{*}=\frac{\sum_{j=1}^{m} j \overline{K_{j}}(N)}{\sum_{j=1}^{m} \overline{K_{j}}(N)}
$$

$\mathrm{m}$ is the total number of species of evaluating degree; $\mathrm{Kj}(\mathrm{N})$ is standardized treatment results for multiple index comprehensive correlation, whose computation formula is:

$$
\overline{K_{j}}(N)=\frac{K_{j}(N)-\min K_{j}(N)}{\max K_{j}(N)-\min K_{j}(N)}
$$

\section{Application instance}

Taking three evaluating photovoltaic power generation project A, B, C in Shaanxi for example, using extension model to evaluate its quality.

Step 1: Establish the photovoltaic power generation project quality evaluation index system and the weight. After the investigation from 15 experts, we use G1 method to determine the index 
system of ci and each index weight $\mathrm{W}$, as shown in table 1.

Step 2: Divide the evaluation degree. In this paper, the photovoltaic power generation project quality evaluation degree is divided as excellent, good, normal ,poor.

Step 3: Determine the photovoltaic power generation project extension matter-element model and take a quality evaluation of a photovoltaic power generation project, as shown in table 2 .

Table.2 The matter-element model and A project for assessment

\begin{tabular}{|c|c|c|c|c|c|c|}
\hline \multirow{2}{*}{ Index } & \multicolumn{4}{|c|}{ Four classical field matter-element $\mathrm{R}$} & \multirow{2}{*}{$\begin{array}{c}\text { joint domain } \\
\text { matter-element } \\
\mathrm{R}_{\mathrm{N}}\end{array}$} & \multirow{2}{*}{$\begin{array}{c}\mathrm{A} \\
\text { project matter-elemen } \\
\mathrm{t} \\
\mathrm{R}_{\mathrm{x}} \\
\end{array}$} \\
\hline & Poor & Normal & Good & Excellent & & \\
\hline C1 & {$[4,6]$} & {$[3,4]$} & {$[2,3]$} & {$[0,2]$} & {$[0,6]$} & 3.4 \\
\hline $\mathrm{C} 2$ & {$[0,3780]$} & {$[3780,5040]$} & {$[5040,6300]$} & {$[6300,6800]$} & {$[0,6800]$} & 5837 \\
\hline C3 & {$[0,2100]$} & {$[2100,2400]$} & {$[2400,2700]$} & {$[2700,3000]$} & {$[0,3000]$} & 2447.8 \\
\hline $\mathrm{C} 4$ & {$[500,1000]$} & {$[300,500]$} & {$[100,300]$} & {$[0,100]$} & {$[0,1000]$} & 550.0 \\
\hline C5 & {$[500,1000]$} & {$[300,500]$} & {$[100,300]$} & {$[0,100]$} & {$[0,1000]$} & 207.5 \\
\hline C6 & {$[0,150]$} & {$[150,300]$} & {$[300,450]$} & {$[450,600]$} & {$[0,600]$} & 372.1 \\
\hline $\mathrm{C} 7$ & {$[0,0.5]$} & {$[0.5,1.5]$} & {$[1.5,2.5]$} & {$[2.5,3.5]$} & {$[0,3.5]$} & 0.98 \\
\hline C8 & $\begin{array}{c}{[12000,} \\
14000]\end{array}$ & {$[10000,12000]$} & {$[8000,10000]$} & {$[0,8000]$} & {$[0,14000]$} & 10196.3 \\
\hline C9 & {$[0,1000]$} & {$[1000,1200]$} & {$[1200,1400]$} & {$[1400,1600]$} & {$[0,1600]$} & 1322.6 \\
\hline C10 & {$[0,1]$} & {$[1,2]$} & {$[2,3]$} & {$[3,4]$} & {$[0,4]$} & 2.7 \\
\hline C11 & {$\left[0,2 * 10^{-3}\right]$} & $\begin{array}{c}{\left[2 * 10^{-3},\right.} \\
\left.4 * 10^{-3}\right]\end{array}$ & $\begin{array}{c}{\left[4 * 10^{-3},\right.} \\
\left.6 * 10^{-3}\right]\end{array}$ & $\begin{array}{l}{\left[6^{*} 10^{-3},\right.} \\
\left.8 * 10^{-3}\right]\end{array}$ & {$\left[0,8^{*} 10^{-3}\right]$} & $4.9 * 10^{-3}$ \\
\hline C12 & {$[0,10]$} & {$[10,15]$} & {$\left[\begin{array}{ll}15, & 20]\end{array}\right.$} & {$[20,25]$} & {$[0,25]$} & 15.97 \\
\hline $\mathrm{C} 13$ & {$[0,0.3]$} & {$\left[\begin{array}{lll}0.3 & 0.9\end{array}\right]$} & {$[0.9,1.8]$} & {$[1.8,3.6]$} & {$[0,3.6]$} & 2.05 \\
\hline C14 & {$[0,90]$} & {$[90,120]$} & {$[120,150]$} & {$[150,180]$} & {$[0,180]$} & 141.6 \\
\hline
\end{tabular}

Step 4: calculate the associated values $\mathrm{Kx}$ using formula (1), formula (2) to calculate a photovoltaic power generation project evaluation indexes and the evaluation degree of associated values, the results are shown in table 3.

Table.3 A PV power generation project indicators about the associated value of each evaluation class

\begin{tabular}{|l|c|c|c|c|}
\hline index degree & Poor & Normal & Good & Excellent \\
\hline C1 & -0.188 & 0.400 & -0.133 & -0.350 \\
\hline C2 & -0.681 & -0.453 & 0.367 & -0.325 \\
\hline C3 & -0.386 & -0.080 & 0.160 & -0.314 \\
\hline C4 & 0.100 & -0.100 & -0.357 & -0.500 \\
\hline C5 & -0.585 & -0.308 & 0.463 & -0.341 \\
\hline C6 & -0.494 & -0.240 & 0.481 & -0.255 \\
\hline C7 & -0.329 & 0.480 & -0.347 & -0.608 \\
\hline C8 & -0.322 & 0.098 & -0.049 & -0.366 \\
\hline C9 & -0.538 & -0.307 & 0.387 & -0.218 \\
\hline C10 & -0.567 & -0.350 & 0.300 & -0.188 \\
\hline C11 & -0.483 & -0.225 & 0.450 & -0.262 \\
\hline C12 & -0.398 & -0.097 & 0.194 & -0.309 \\
\hline C13 & -0.530 & -0.426 & -0.139 & 0.139 \\
\hline
\end{tabular}

Step 5: evaluation degree

Using the formula (3) to calculate A photovoltaic power generation project and comprehensive correlation degree of each evaluation degree refer to which we can calculate the photovoltaic power generation project $\mathrm{B}, \mathrm{C}$ and their comprehensive correlation degree of each evaluation class the results are shown in table 4. 
Table.4 By evaluating project A, B, C and the evaluation class of comprehensive correlation degree

\begin{tabular}{|c|c|c|c|c|c|}
\hline & Poor & Normal & Good & Excellent & Belongs to degree \\
\hline A & -0.417 & -0.126 & 0.145 & -0.309 & Good \\
\hline B & -0.169 & -0.008 & -0.279 & -0.274 & Normal \\
\hline C & -0.526 & -0.318 & -0.043 & -0.183 & Good \\
\hline
\end{tabular}

The table shows that the comprehensive quality of photovoltaic power generation project $\mathrm{A}$ and $\mathrm{C}$ are on the same rating, at this time we can use the formula (4), (5) to calculate the level of bias characteristic value $j^{*}$, the greater $j^{*}$ is, the better comprehensive quality of the project will be. The results are shown in table 5.

Table.5 PV power generation project evaluation: A, C grade bias characteristic value

\begin{tabular}{|l|l|}
\hline PV power generation project & $j^{*}$ \\
\hline A & 2.629 \\
\hline C & 2.912 \\
\hline
\end{tabular}

Above all: the comprehensive quality of three photovoltaic power generation projects in shaanxi province 2012 from high to low in turn is C,A,B.

\section{Conclusion}

(1) The photovoltaic power generation project quality evaluating method based on the theory of the extension evaluation use the basic nature of matter element to give a qualitative description of photovoltaic power generation project. Combined with the correlation functions of extension project photovoltaic power generation project can be analysed quantitatively and the evaluation results are more scientific, objective and accurate.

(2) The extension evaluation method can not only give a comprehensive judgement on evaluating the comprehensive quality of the project, but also can reflect the degree of membership of each index on its evaluating degree, from which can provide the improvement of photovoltaic power generation project effectively [4].

\section{References}

[1] Yang Chunyan, Cai wen,Extension engineering, Science press:Beijing,pp.9-10,2007.

[2] Tian Junli,Photovoltaic (pv) power generation under low carbon economy comprehensive benefit evaluation study, Northwest electric power university:Beijing,pp.18-20,2013.

[3] Meng ting. Based on the matter-element theory of extenics method of power quality comprehensive assessment research [J]. Mechanical and electronic information, 2011, 24: 232-235. [4] He Yabo, Shuai Qingyan,Green building comprehensive evaluation based on extension theory,Building science, 12,pp.90-93,2012. 